\title{
De tribus y etnias: transformaciones históricas y vinculación con los Estados-nación
}

\author{
Antonela dos Santos Montangie
}

Maurice Godelier, 2010

Les tribus dans l'Histoire et face aux États

CNRs Éditions, París, 80 pp.

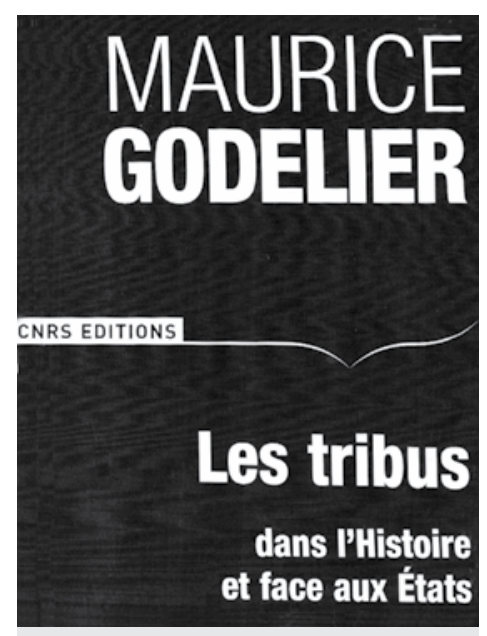

et face aux États

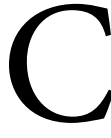

omo producto de la revisión de la conferencia inaugural de Maurice Godelier en el coloquio internacional The Political Role of Tribes in the Middle East - pronunciada en Amánn, Jordania, en 2009- sale a la luz esta breve obra intitulada, en idioma original, Les tribus dans l'Histoire et face aux États. En ella el autor propone revisar el lugar que los grupos tribales han ocupado en la historia y el modo en que se han relacionado con los Estados. El texto se estructura en cuatro secciones. En la primera se hace una distinción analítica entre los conceptos de "tribu" y "etnia", y a partir de su definición se puntualizan las diferencias respecto de las formas de ordenación social que cada uno implica. Godelier sostiene que las sociedades tribales, en tanto ordenación social basada en lazos de parentesco, funcionan como una sociedad y asegura a sus miembros la dinámica más inmediata: el acceso a la tierra, a las mujeres y a la protección. La etnia, por su parte, en tanto comunidad cultural y lingüística de grupos locales diferentes, les proporciona una vinculación identitaria. 
La segunda sección pasa revista de manera acotada a la diversidad de tribus del mundo $y$ las formas en que se organizan políticamente: desde las sociedades basadas en clanes patrilineales hasta aquellas en las que se vislumbran signos de la formación de aristocracias permanentes que podrían dar lugar a los Estados, pasando por las que conformaron jefaturas hereditarias o se estructuraron de manera segmentaria. Una vez definidos los grupos tribales $\mathrm{y}$ descritas las configuraciones que adoptaron en diversas regiones, la tercera sección profundiza en los momentos de conformación de los Estados y hace énfasis en el papel que las tribus desempeñaron en este proceso histórico. A lo largo del tiempo, esta articulación entre tribus y Estado adquiere dos formas fundamentalmente: la ordenación tribal se incorpora a la estatal y ambos niveles coexisten y comparten la soberanía, o las tribus terminan desapareciendo porque el Estado las subordina y las margina.
Por último, la cuarta sección de esta obra introduce una suerte de genealogía de la aparición y conformación de los Estados en la que se detallan los cambios socioculturales y materiales del periodo neolítico con base en los cuales se desarrolló este proceso. Puede decirse que se trata del momento menos concluyente de la exposición porque, si bien el autor da testimonio de la importancia de las incipientes relaciones que se establecieron entre los grupos tribales y las ciudades recientemente creadas, la disertación se torna un tanto general y no da suficientes respuestas respecto de la forma que adoptó el pasaje de las sociedades basadas en el parentesco a las sociedades estatales. La obra culmina con una reflexión de Godelier sobre la situación de Iraq después de la invasión estadounidense, que para él puede aclararse al tener en cuenta cómo las solidaridades tribales siguen presentes allí y se fortalecen y reaparecen siempre que el aparato estatal, por algún motivo interno o externo, se ve desarticulado. Estas conclusiones parciales a las que arriba el autor pueden exceder el ámbito de Medio Oriente e iluminar otras realidades. En un contexto latinoamericano en el que la discusión sobre las minorías étnicas tiene un papel preponderante, lecturas como ésta pueden proveer aportes valiosos. La situación actual de los pueblos indígenas americanos $\mathrm{y}$ los diversos, y muchas veces conflictivos, modos en que éstos se relacionan con contextos estatales más amplios, lejos de ser un tema saldado, propone desafíos importantes a la antropología en tanto disciplina. En su libro, Godelier sostiene la necesidad de conocer los modos en que la academia ha teorizado a lo largo de la historia sobre las tribus. Se recomienda la lectura de esta obra no sólo porque permite avanzar en ese sentido, sino porque nos recuerda la pertinencia de revisar categorías y de reflexionar sobre las posibilidades y las restricciones teórico-metodológicas que su uso supone. 